\title{
La migration du folklore et des fêtes germaniques au Sud du Brésil
}

Germanic Folklore and Feasts in Southern Brazil

La migración del folklore y de las fiestas germano-brasileñas en el Sur del Brasil

\section{Séverine Malenfant}

\section{(2) OpenEdition}

Édition électronique

URL : https://journals.openedition.org/remi/4997

DOI : 10.4000/remi.4997

ISSN : $1777-5418$

Éditeur

Université de Poitiers

Édition imprimée

Date de publication : 1 décembre 2009

Pagination : 153-165

ISBN : 978-2-911627-53-8

ISSN : 0765-0752

Référence électronique

Séverine Malenfant, « La migration du folklore et des fêtes germaniques au Sud du Brésil », Revue européenne des migrations internationales [En ligne], vol. 25 - n³ | 2009, mis en ligne le 01 décembre 2012, consulté le 15 avril 2022. URL : http://journals.openedition.org/remi/4997 ; DOI : https://doi.org/ 10.4000/remi.4997 


\title{
La migration du folklore et des fêtes germaniques au Sud du Brésil
}

\author{
Séverine MALENFANT*
}

Au cours de son histoire, le Brésil a connu des courants successifs d'immigration suscitant une riche diversité folklorique. Dans l'État de Santa Catarina, « le plus allemand du Brésil », les fêtes germano-brésiliennes méritent une série de questionnements concernant les relations interethniques, à laquelle vient s'ajouter une réflexion sur la notion de transfert culturel.

La première partie se penche sur l'histoire de la colonisation allemande. Nous verrons comment les migrants ont maintenus des traits folkloriques germaniques et ce qu'il en est advenu en situation de contact après migration. Nous présenterons les phénomènes de réinterprétation de biens culturels importés ainsi que le transfert de modèles politiques. L'objectif principal est d'analyser les dernières actualisations de la culture germano-brésilienne et notre intérêt porte ici sur quatre manifestations de l'État de Santa Catarina qui compte actuellement la plus importante population germano-brésilienne du pays. En 2007, Blumenau organisa sa 24e Oktoberfest, Pomerode sa 24e Festa Pomerana, Timbó sa 17e Festa do Imigrante et Jaragua do Sul fêta sa 19e Schützenfest. Nous pourrons restituer leur genèse historique, évaluer les conditions de leur production et suivre leur invention en cernant les stratégies, intérêts et attitudes prises par leurs organisateurs. Si ces fêtes revendiquent une identité allemande, quelle en est leur matière première ? Finalement, il importera d'observer les fonctions de célébration, de transgression et de participation. Ces fêtes sont-elles des institutions génératrices de spontanéité, des facteurs d'alliance et de cohésion?

\section{LA MIGRATION DU MYTHE DE LA GERMANITÉ. NAISSANCE ET DÉCLIN DU FOLKLORE GERMANO-BRÉSILIEN}

Avec l'objectif de blanchir la population et de coloniser des régions peu exploitées, les autorités brésiliennes appelèrent des colons en provenance de la Confédération

\footnotetext{
* Membre du Centre de Recherche sur les Conflits d'Interprétation (EA 3824), CIL, Nantes et du Centre interdisciplinaire d'études et de recherches sur l'Allemagne ; severine.malenfant@ hotmail.fr
} 
germanique dès 1824 . Ces « faiseurs de terres » intervinrent en pionniers comme de véritables « colons » (du latin colere : mettre en valeur un espace). Ils construisirent des routes, défrichant la forêt vierge et se consacrant à l'agriculture. Ils s'adaptèrent à leur nouveau milieu et modifièrent leurs habitudes quotidiennes, tout en formant des villages, des « colonies enkystées à l'intérieur du Brésil » (Bastide, 1957), parlant leur langue, ayant leurs prêtres et leurs écoles. Plus importantes qu'en Allemagne, les sociétés récréatives permettaient de résoudre les problèmes d'ordre éducatif, spirituel et économique. Outre sa finalité culturelle, la Kulturverein (1873) de Blumenau prêtait assistance à l'administrateur de la colonie à travers des expositions et la mise en valeur de manuscrits. Mais la plus ancienne est la Société de tir Schützenverein (1859). En effet, la pratique de la chasse fut longtemps une nécessité et l'arme à feu un moyen de se défendre face aux indigènes et aux bêtes sauvages. Espace important de sociabilité, cette Société réalisait annuellement une Schützenfest avec des compétitions de tirs, l'élection du roi et de la reine et un bal où l'on consommait de la bière au son de musiques allemandes. Elle intégrait d'autres activités comme le chant (la présentation des Lieder), le théâtre ou les danses folkloriques. La Schulverein avec ses fêtes écolières et les Turnverein (Sociétés de gymnastique) avaient également coutume de participer aux manifestations de la Schützenverein. Ces fêtes fonctionnaient comme espaces d'actualisation d'une identité culturellement marquée par la germanité et reconfigurées dans la nouvelle patrie. À la fin du XIXe siècle, elles devinrent des centres de préservation d'un folklore artificiel, sanctuaires de sauvegarde du germanisme.

Outre les motivations économiques, les adeptes de l'Impérialisme allemand espéraient l'avènement d'une République teuto-brésilienne, séparée du reste du Brésil. La diffusion du Deutschtum fut réalisée par les autorités politiques et ecclésiastiques qui cherchaient à renforcer dans la population le sentiment d'appartenance à une communauté ethnique supranationale (Volkstum). À partir du 1er janvier 1906, l'administration coloniale n'entendait soutenir que les écoles décidées à diffuser la culture allemande. Centre de résistance culturelle et linguistique, l'Église évangélique prônait l'endogamie et, par crainte ancestrale de «l'impureté du sang », l'autarcie perdura dans les colonies. La notion de germanité confortait l'idée que la nationalité est héritée et qu'un Allemand reste un Allemand, même s'il naît dans un autre pays. Il s'agissait de "revigorer la germanité » dans des régions trop «brésilianisées » (verbrasilianert, tombées dans le Brasilianertum) (Klug, 1991). En effet, la communauté germano-brésilienne se transforma malgré elle, soumise à la pression exercée par l'économie urbaine. Résultat d'un premier syncrétisme interrégional, elle passa à une seconde étape, celle du syncrétisme avec la civilisation brésilienne. Et à cette hétérogénéité s'ajouta celle des générations. Le terme « teuto-brésilien »(Deutschbrasilianer) surgit dans la deuxième moitié du XIXe siècle, lorsque les colonies sortirent de leur isolement. Petit à petit se formait une nouvelle identité, une « civilisation syncrétique » (Bastide, 1957), ayant en même temps des éléments empruntés à la culture germanique et d'autres empruntés à la culture locale. Le Germano-brésilien était parfaitement adapté à ce monde mixte et il se distingua des nouveaux immigrants allemands. Gagnant la ville et s'élevant dans l'échelle sociale, il apprit le portugais pour s'intégrer dans le système économique national. Si en 1930, la langue d'enseignement restait majoritairement l'allemand, $40 \%$ de la population de Blumenau était lusophone. En réalité, les immigrants venaient de régions très diverses et parlaient différents dialectes. Ils étaient confrontés à une sorte de Babel linguistique à l'intérieur de leur propre commu- 
nauté et utilisaient un créole truffé d'emprunts au portugais (Willems, 1946).

Dans les années trente, le parti nazi reprit la vieille rhétorique de la supériorité raciale des Allemands en introduisant une nouvelle catégorie identitaire - Volksgenosse (compatriote) - liant l'origine allemande et l'appartenance au parti, radicalisant les présupposés de la germanité. Le Reich envoya des expéditions au Brésil, considéré comme " laboratoire racial » et l'Institut Tropical de Hambourg décréta en 1936 que " la race aryenne pouvait survivre dans les tropiques, à condition qu'elle ne se mélange pas à la population locale » (Dietrich, 2007). Le nazisme subit une «tropicalisation », car l'antisémitisme céda la place à un racisme envers les Noirs et les Métis. Certains colons allaient jusqu'à importer des jeunes filles aryennes, car les « Allemands purs » étaient considérés supérieurs aux Germano-brésiliens, la génération née au Brésil. Cette division effectuée par les nazis entraîna la création d'un mouvement fasciste à la brésilienne, l'Alliance Intégraliste Brésilienne (AIB), qui compta un nombre important d'adhésions dans les communautés germano-brésiliennes. Elle voulait assimiler les communautés allemandes au Brésil tout en réduisant le métissage pour « améliorer la race». Le parti nazi la qualifia néanmoins de nativiste et « lusitanisante », représentant une menace pour la germanité au Brésil (Dietrich, 2007).

Avec José Ferreira da Silva, l'Alliance Intégraliste promut la mémoire du fondateur Hermann Blumenau dont elle érigea la statue. Son règne fut marqué par une production historiographique importante. Blumenau comptait alors 100000 habitants dont $53 \%$ de germanophones et $49 \%$ de protestants, dispersés sur un territoire de $10375 \mathrm{~km}^{2}$. La région n'était donc pas culturellement homogène, mais il y avait une préoccupation de la part de l'élite d'investir dans l'idée de frontière ethnique. Le 26 janvier 1934, le démembrement territorial réduisit la municipalité à une superficie de $1650 \mathrm{~km}^{2}$. Indignée, la population manifesta dans les rues de Blumenau avec des slogans proclamant l'union de tous les descendants d'Allemands (Frotscher, 2007). Les organisateurs, fonctionnaires de la mémoire, soumirent l'histoire locale à une manipulation discursive, valorisant les mythes fondateurs et concevant la « grande Blumenau » au dessus des divisions politiques municipales. Ils développèrent un discours régionaliste afin de promouvoir une unité culturelle et maintenir une frontière ethnique, construisant un « nous » en opposition à « eux » : «Tous les descendants d'Allemands sont allemands, nationalement parlant, à condition de préserver la langue maternelle allemande, les traditions et habitudes allemandes » (Entres, 1929).

Entre 1934 et 1938, les fêtes commémoratives abondèrent : le 2 septembre (fondation officielle du municipe), le 7 septembre (l'Indépendance du Brésil), le 25 juillet (Jour du Colon) et dans le milieu germanophone, on célébrait également la fête nationale allemande du 30 janvier (élection d'Adolf Hitler), le 20 avril (anniversaire du Führer) et le premier mai (jour du travail). Les festivités du «Jour du Colon » (Dia do Colono) rendaient hommage aux descendants des Allemands exclusivement, à la culture allemande comme ciment d'une région indivisible. Jusqu'en 1939, des journaux exaltant la valeur du peuple allemand et sa supériorité sur les Brésiliens circulaient dans les colonies. Des jugements de valeur et clichés ethnocentriques célébraient « le travail allemand » et dénigraient la tradition créole. Cependant, la propagande du parti nazi n'empêcha pas les descendants d'immigrants de réaffirmer, sinon leur opposition à l'hitlérisme, du moins 
le principe d'une double appartenance à l'héritage culturel allemand et à la patrie brésilienne. Ils voulaient garder leur originalité, leur position " marginale » (Bastide, 1957). Ainsi dans les années trente, le postulat de la germanité (Deutschtum) se transforma définitivement en " germanité brésilienne " (Deutschbrasilianertum), une conciliation de l'origine allemande et de la nationalité brésilienne (Richter 1992). En 1937, avant même la nationalisation de l'enseignement, un grand nombre d'écoles avaient déjà introduit la langue portugaise dans leur programme. Et contrairement à une rumeur persistante, les Allemands arrivés dans les années quarante comptaient bien plus de réfugiés politiques et de Juifs persécutés que de chefs nazis en cavale (Blancpain, 1994).

Au début des années trente, les descendants d'immigrants pouvaient exercer leur profession et organiser des fêtes sans aucune restriction relative à la langue, à la religion ou à la tradition germanique. Cependant à partir de 1937, des mesures drastiques de nationalisation furent prises à leur égard. Dans le but de créer la « brésilianité » (brasilidade), Gétulio Vargas décréta la Campanha de Nacionalização, prenant pour cible les colonies du Sud du Brésil et tout particulièrement les immigrants d'origine allemande. Des localités, des rues et des associations furent débaptisées et "brésilianisées ». On mit à sac des institutions et des magasins allemands. S'ensuit un train de décrets-lois visant à intégrer, de force si nécessaire, "les colonies réputées étrangères dont la brésilianité est jugée suspecte ou insuffisante » (Vargas, 1935) : interdiction de la presse en langue allemande et nationalisation de l'enseignement. Les écoles furent restructurées en " écoles nationales » et le portugais devint langue officielle (Monteiro, 1984). A Blumenau, la campagne fut assez violente en raison des forces politiques qui dirigeaient la ville, l'Alliance Intégraliste et le Parti national-socialiste (NSDAP), actifs dans la sphère publique. Les fêtes écolières et religieuses furent surveillées par la police et par le DOPS (Departamento de Ordem Politica e Social) et un bataillon de l'armée s'installa dans les locaux de la Société de tir en 1938. Le 10 mars 1940, la municipalité reçut la visite de Gétulio Vargas. Dans un discours applaudi dans tout le pays, le président exprima sa surprise devant une population qui aurait soi-disant « méconnu la langue brésilienne ». Il insista ensuite sur la neutralité du Brésil dans les conflits européens : «(...) Aujourd'hui, cette population d'origine coloniale qui exerce ses activités au sein de notre terre est brésilienne. Et vous tous, vous êtes Brésiliens, parce que vous êtes nés au Brésil et que le Brésil vous a donné une éducation. (...) Être Brésilien, c'est aimer le Brésil. Si le Brésil nous a donné du pain, nous lui donnerons notre sang. " (Vargas, 1940). Mais la déclaration de guerre à l'Allemagne aggrava les tensions. L'usage de la langue allemande fut interdit et des préjugés racistes accablaient les descendants des immigrants d'origine germanique, disqualifiés par leur « disposition héréditaire » à l'agression. Aux yeux des Brésiliens, Blumenau était un « kyste racial », "un Brésil égaré en mains étrangères ». En sens inverse, les préjugés lusophobes se cristallisent, repris du pangermanisme et dénonçant la "paresse congénitale » et la "malhonnêteté incorrigible » du Noir ou du Métis (Blancpain, 1994). Deux forces s'opposaient. L'une poussait la communauté à se protéger de l'extérieur et l'autre contribuait à la désagrégation du groupe et donc à son assimilation progressive.

Après la guerre, certaines restrictions continuèrent à s'imposer. Jusqu'en 1954, les services culturels de la République Fédérale mettaient en garde les Sociétés allemandes contre l'abus des libertés dont elles jouissaient. L'usage de la langue fut autorisé pour la population mais bannie des programmes scolaires et des publications littéraires. 
L'allemand se trouva limité au foyer, aux relations familiales et aux cultes religieux. Son apprentissage se fit par la tradition orale, ce qui contribua à sa transformation et à son appauvrissement grammatical. Avec le processus de nationalisation, le mythe de la germanité ancré dans l'inconscient collectif s'essouffla ainsi que la vie associative. Cependant, cela ne signifie pas pour autant la disparition de cette mémoire minoritaire, car si elle ne s'exprimait pas publiquement, elle était transmise clandestinement d'une génération à l'autre et restait liée au souvenir affectif de la mère patrie, vivant dans les sentiments et attitudes, comme une réalité spirituelle. La mobilité des groupes n'empêcha donc pas une certaine cristallisation folklorique. Malgré toute leur loyauté envers la nouvelle patrie, les immigrants et leurs descendants entretenaient dans un coin de leur cœur le jardin secret du pays abandonné, «le myosotis germanique » (Bastide, 1957). En outre, cette mémoire souterraine et silencieuse trouva un moment propice pour revenir à la lumière du jour dans les années cinquante.

\section{RÉSURRECTION ET RECOMPOSITION DU FOLKLORE : INVENTION DE LA CITÉ TOURISTIQUE ET CONSTRUCTION DES FÊTES}

En 1950, Blumenau commémora le centenaire de sa fondation, valorisant les mythes fondateurs et mettant sous silence le passé proche. Ni la campagne de nationalisation, ni l'Intégralisme au pouvoir entre 1936 et 1938 et encore moins les activités du NSDAP local ne furent mentionnés dans le livre commémoratif de 1950. Dans les années soixante, la ville se fit connaître sous le nom de "petite Allemagne » avec une campagne publicitaire intitulée « Devine quel est ce pays ? (Adivinhe que pais é este?). On organisa un Festival de la bière (Festival da Cerveja) et à cette occasion, on exposa les reliques mais personne n'y dansait la valse sur une musique allemande (Jornal de Santa Catarina, 25/02/1973 et 31/01/1978). En 1971, la Commission du tourisme mit en place un plan d'action afin de promouvoir l'identité germanique : conservation du patrimoine historique et aide fiscale pour la construction de maisons à colombages. On enjoliva le centre-ville, on ouvrit un kiosque d'informations et un restaurant typiquement allemand. Les militants de l' "Alemanha Brasileira » allèrent chercher des modèles en Allemagne, tel le Petit Château (magasin de souvenirs Moellmann), inspiré de l'Hôtel de ville de Michelstadt. On construisit une cité touristique, liant l'Allemagne et le Brésil dans un même scénario urbain. Les mendiants furent expulsés et les favelas devinrent des quartiers invisibles. Les édifices (l'Hôtel de ville, la Casa Flamingo, le Musée Colonial) furent revêtus d'un nouveau costume germanique. Avec son faux colombage et ses pastiches, ce «Blumenland» se mit à cultiver le simulacre et la citation. Il fut imaginé et dessiné par la Commission municipale du tourisme, seul lieu institutionnel de cette invention. En 1971, cette Commission rejeta le projet d'ouvrir une école de samba à Blumenau, prétextant qu'elle pourrait nuire à la culture germanique, à la ville "monophonique ». La même année, la chanteuse Elisete Cardoso refusa une invitation au Club de Tennis Tabajara, prétextant que la ville était raciste. On discuta alors des actions à engager afin de changer cette image. On commença par faire le registre des touristes étrangers et on organisa un échange avec les villes voisines (Ramos Flores, 1997). C'est aussi à cette époque que germa l'idée d'organiser l'Oktoberfest. 
Après une longue période de gestation, l'Oktoberfest fut organisée en 1984 suite à deux grandes inondations. Alors que des entreprises menaçaient de quitter la ville, Dalto dos Reis, maire élu en 1983, donna son appui à sa création. Les re-créateurs du folklore promettaient de montrer au public toutes les traditions des colons allemands. Ils se rendirent spécialement à Munich pour voir comment fonctionnait l'Oktoberfest bavaroise : «Depuis longtemps à Blumenau, nous avions l'idée d'utiliser l'image germanique. Il fallait faire vite, avant Joinville ou São Bento. Les inondations furent une véritable aubaine puisque dans tout le pays, les médias parlaient beaucoup de Blumenau. Les touristes furent sensibilisés, tout comme la population locale. » (Schramm, 1993). De façon parfois obsessionnelle, l'authenticité préoccupa les groupes folkloriques qui firent des recherches minutieuses sur les costumes, les musiques et les danses traditionnelles. Les archives furent revisitées et on fit appel au travail des historiens. La ville revêtit un aspect encore plus typique. Les maisons furent repeintes en blanc et rouge, les couleurs officielles de la municipalité. On organisa plusieurs manifestations culturelles dont un défilé avec les Sociétés de tir, les fanfares et les groupes folkloriques, à l'époque en petit nombre. Des meubles anciens furent par exemple exposés sur le char "Sala Colonial ». Les costumes furent copiés sur ceux des groupes folkloriques allemands. On fit venir des fûts de bière d'Allemagne ainsi que des fanfares. Il s'agissait de "retendre les liens avec la patrie-mère », notait le journal de Santa Catarina le 24 août 1984. L'initiative vint avant tout des entreprises locales dont l'objectif était de créer une attraction pour le mois d'octobre, période de faible fréquentation touristique. En effet, la fête fut un véritable succès en termes de public et de litres de bière consommés. Depuis 1984, Blumenau promeut son Oktoberfest comme « la deuxième fête de la bière au monde » et « la plus importante des Amériques ».

La fête de Pomerode apparaît la même année que l'Oktoberfest de Blumenau. Si la municipalité ne fut pas directement touchée par les inondations, les effets se firent néanmoins sentir sur son économie. On commença à préserver l'architecture et à rassembler les antiquités et les documents historiques. On s'intéressa aux témoignages des anciens afin de reconstruire l'histoire des pionniers. Un premier fascicule historique fut publié en 1983. L'idée de la Festa Pomerana surgit cette année-là. Comptant sur l'aide du gouvernement, le conseil municipal travailla en collaboration avec les industriels et commerçants. Il organisa toute l'infrastructure et définit les attractions : une foire exposant les produits locaux, des plats typiques et un concours culinaire, des danses folkloriques et des bals animés de musique allemande. La première eut des répercussions positives sur la localité. En 1989, les écoles municipales introduisirent l'allemand dans leur programme et la municipalité engagea une recherche sur les spécificités de Pomerode : «la descendance poméranienne, l'origine commune de la majeure partie de la population, l'usage accentué de l'allemand et du dialecte Pommersche Plattdeutsch, le protestantisme d'origine luthérienne comme religion dominante, l'indice élevé d'alphabétisation, la main-d'œuvre qualifiée, le nombre important de maisons à colombage, 16 sociétés de chasse et de tir et des fanfares ». De ces résultats est née la phrase « Pomerode, la ville la plus allemande du Brésil » (Pomerode, a cidade mais alemã do Brasil), largement divulguée par les moyens de communication (Zimmer, 1997). Si en 2009 les germanophones sont une minorité dans la région, la ville de Pomerode fait exception à la règle. Près de $80 \%$ de sa population parle encore allemand couramment. En effet, elle resta plus longtemps isolée de ses voisines et le dialecte de Poméranie était parlé par la majorité des colons. De plus, ceux-ci étaient luthériens et l'allemand est demeuré la langue du culteDans les années quatre- 
vingt, un nouveau calendrier folklorique apparaît, motivé par le succès de l'Oktoberfest : la Fenachopp de Joinville, la Fenarreco de Brusque, la Musikfest de São Bento et la Kegelfest de Rio do Sul en 1986, la Schützenfest de Jaraguá do Sul en 1989 et la Festa do Imigrante alemão de Timbó en 1991. Contrairement aux villes de Pomerode et de Blumenau, Timbó fait coexister plusieurs folklores et ne se contente pas de reconstruire une mémoire germanique. En 2000, la Fête de l'Immigrant allemand devint Fête de l'Immigrant, "dans le but de préserver l'héritage des ancêtres et de maintenir l'accès à la flamme de la culture germano-italienne de Timbó » (Milani, 2007). À Jaraguá do Sul, les constructeurs de folklore trouvèrent leur matière première dans les traditionnelles Sociétés de chasse et de tir qui confèrent un substrat culturel et une légitimité à leur fête. Le cortège des Sociétés prend son départ devant un mât orné de rubans, un arbre de mai dressé ici au mois d'octobre, témoin d'un folklore mobile et artificiel jaillissant d'une mémoire en conflit avec le renversement des saisons. Avec 85000 visiteurs en octobre 2007, elle serait « la plus grande fête des tireurs des Amériques, la plus authentique des fêtes allemandes du Brésil, la seule qui préserve intégralement la tradition. (...) La Schützenfest existe aussi à Hanovre en Allemagne. Le maire, le secrétaire de la culture et le président des Sociétés de tir y ont assisté. Il s'agit du même rituel. » (Rodrigues, 2007).

Ces fêtes se veulent donc authentiques, préservant la culture allemande. En effet, elles ont réanimé certaines traditions comme les compétitions des Sociétés de tir. Cependant, la majeure partie de la culture qu'elles présentent fut réinventée lors de leur création dans les années quatre-vingt. Jusqu'en 1983, l'unique groupe de danses folkloriques de la région était l'Alpino Germânico de Pomerode. En outre, le costume traditionnel à jupe courte porté dans les cortèges n'a pas grand-chose à voir avec la culture allemande. Personne ne porte de telles «Tracht» dans les fêtes de Dinkelsbühl, de Rothenburg ou de Munich. Le destin de ces fêtes est donc le même que celui du monument. À l'instar des cités touristiques, elles sont des inventions stéréotypées qui combinent divers éléments culturels, divers imaginaires et diverses représentations du passé. Elles peuvent être analysées comme compositions, processus de création culturelle et de réinvention des traditions. Elles n'ont pas surgi spontanément, de manière informelle ou anomique. Elles furent pensées et orientées par des commissions composées de membres du Conseil municipal, des commerçants et industriels dont l'intérêt était de réunir tous les éléments liés à la germanité, à l'origine et au passé, afin de rendre leur fête encore plus typique. Elles exercent aujourd'hui encore une grande influence, au-delà de l'organisation des fêtes. À Pomerode, la commission organisatrice donne son avis sur les projets de construction et d'occupation de l'espace et elle agit contre toute action portant préjudice à l'image de « la ville la plus allemande du Brésil ».

\section{LES FÊTES GERMANO-BRÉSILIENNES, ENTRE TRANSGRES- SION ET CÉLÉBRATION, PARTICIPATION ET EXCLUSION}

Nombre d'indices nous montrent que les fêtes germano-brésiliennes sont guidées par une logique économique. En effet, cette tradition inventée est créatrice d'emplois et enveloppe des intérêts divers. Elle est surtout une véritable opération commerciale pour les quatre grandes brasseries brésiliennes qui se disputent le droit d'explorer les pavillons. La culture allemande est exposée et consommée : poupées allemandes, tee- 
shirts, chapeaux et coucous tyroliens, culottes de cuir, choppes en aluminium... « La seule chose typique que Blumenau puisse vendre est sa culture germanique », confirme Emilio Schramm (1993). Peu accessible à beaucoup de Brésiliens pour des raisons financières, l'Oktoberfest s'inscrit dans un mouvement d'économie touristique dont l'effet peut être désocialisant. Comme beaucoup de fêtes aujourd'hui, elle induit de façon accélérée le passage à l'acte d'achat. S'ils critiquent la hausse des prix, certains Germano-brésiliens dénoncent aussi la disparition progressive des vraies valeurs communautaires. Ils qualifient péjorativement l'actuelle Oktoberfest de «culture de la chope » : "les fêtes ont cessé d'être les nôtres pour devenir les leurs » (aux Brésiliens, aux touristes) (entretiens réalisés par nous à Blumenau en 2007). Ainsi les fêtes perdraient leur caractère de célébration pour se transformer en spectacle lucratif soumis à l'économie de marché.

Dans les discours officiels cependant, elles sont encore perçues comme des temples de la mémoire collective, ancrés dans une temporalité fondatrice de l'identité. Valorisant l'origine et représentatives de la culture traditionnelle, elles mettent en scène un patrimoine local de manière consensuelle afin de "préserver la mémoire des ancêtres ». Sur des chars allégoriques, des figurants en costume traditionnel miment l'histoire de leur municipalité. Représentant le quotidien des premiers immigrants, le « carro do Imigrante » ou la «casa da família colonial » de Blumenau mobilisent le registre de l'affect collectif et situent les jeunes participants dans la continuité des habitudes de leurs grands-parents. Selon le président de l'Oktoberfest en 1993, "les jeunes redécouvrent les traditions de leurs grands-parents interdites pour des raisons politiques durant une génération entière. » (Pfau, 1993). En 2007, le président de la Schützenfest explique que «chaque peuple a une identité que nous devons, d'une manière ou d'une autre, préserver. Cette culture est le fruit de ceux qui cultivèrent notre ville aujourd'hui prospère. Elle était pratiquée au quotidien avec l'usage de la langue, les vêtements et les manifestations liées au tir, au chant et à la danse. Cette identité doit être préservée et racontée » (Pilon Torres, 2007). Le discours prononcé par le maire de Pomerode en 1989 est également significatif : «La ville de Pomerode est faite d'histoire et de culture. Nous allons montrer avec fierté notre musique, notre danse, notre gastronomie et surtout notre joie de vivre. Tous ensemble, nous allons participer à ce fantastique voyage dans le passé, à une époque où nos ancêtres de 1863, ces braves et hérö̈ques Poméraniens sont arrivés ici pour construire leur foyer. Ils ont apporté leurs traditions dont nous avons hérité et que nous cultivons aujourd'hui encore. » (Drews Filho, 2007). La répétition «notre musique, notre danse, notre gastronomie » revendique une unité, rappelant que l'identité est collective. La pédagogie du sentiment d'appartenance passe par l'emploi répétitif des possessifs de la première personne du pluriel : insistance du «notre » et du « nous » auto-implicatif et marqueur de l'identité du groupe. Or l'action exemplaire des héros tutélaires ne renvoie-telle pas à une mythologie privée, ne reposant que sur ceux qu'elle mobilise ?

Symbole de lutte contre les eaux du fleuve Itajaí, l'Oktoberfest aurait permis la renaissance matérielle et spirituelle de Blumenau. Les constructeurs de fêtes avaient conscience que la catastrophe provoquée par les inondations alimenterait le mythe de la bravoure et du courage du peuple allemand. Ils utilisèrent les symboles de l'identité collective, les mythes de l'authenticité et de la solidarité, idéalisant les grands ancêtres. En effet, les scènes jouées dans les cortèges renvoient à la fondation de la colonie, aux conditions difficiles d'adaptation à la nouvelle terre et au combat contre la forêt vierge mené 
en commun. A Blumenau par exemple, le char de l'Immigrant représente un bateau transportant les dix-sept premiers colons sur le fleuve Itajaí, ces héros qui construisirent seuls leur foyer, transformant la forêt vierge brésilienne en civilisation. À Pomerode, le char du « Holzhacker » (compétition consistant à scier un tronc d'arbre le plus vite possible) renvoie au travail de déforestation effectué par les pionniers. Ainsi les fêtes célèbrent indirectement le « travail allemand » dont le mythe est entretenu par le fort développement économique de la région. En 2007, tout ce qui est allemand ou présumé tel jouit d'un préjugé favorable, d'autant plus que la colonisation a contribué au progrès de l'État et à son achèvement territorial. La catégorie « colons » est utilisée dans les publicités comme indicateur de qualité spécifique au petit propriétaire d'origine. Aujourd'hui, on fait la promotion de l'allemand et cette langue est perçue soit comme marque d'identité spécifique valorisant l'origine, soit comme instrument professionnel, permettant notamment d'obtenir plus facilement un emploi ou une promotion.

Pour faire leur théâtre, les villes germano-brésiliennes mettent en valeur leur exclusivité germanique, excluant parfois ceux qui n'ont pas l'apparence allemande. Chaque année est organisé un concours exaltant la beauté de jeunes filles dont les traits physionomiques rappellent la descendance de la cité. Blondes aux yeux bleus, la reine et les princesses ont la fonction de divulguer leur fête. Leur élection se fait sur le critère de l'élégance et de la «beauté germanique ». Elles doivent parler l'allemand et être membres d'une Société de tir (Rainha da Oktoberfest tem que falar alemão, Jornal de Santa Catarina, 28 mai 1988). À Pomerode, c'est la «jeune fille la plus allemande du Brésil » qui est élue. Une autre figure intéressante est la mascotte Wilfried de Jaraguá créée par la commission en 1998. Il représente un jeune Allemand blond aux yeux bleus, portant la culotte de cuir. Armé d'un fusil, "il est un grand défenseur de la culture germanique " (Prochnow, 2007). On lui confère tous les attributs du bon garçon : charmant, sympathique, ami de tous, charismatique et sérieux car ne buvant pas d'alcool. Ce " tireur-né » masqué est un modèle pour les enfants et il accompagne la reine avec laquelle il anime la fête. Il apparaît comme son protecteur, ce qui lui confère un air patriarcal. Les fêtes proposent un modèle stéréotypé de la famille avec des rôles bien définis. Dans les cortèges, les hommes sont coiffés d'un chapeau indiquant la vie publique. Les femmes portent un tablier, symbole du travail domestique. Le char « La maison de la famille coloniale » de Blumenau met en scène les activités quotidiennes d'un couple : l'homme travaille à l'extérieur et, à l'intérieur du foyer, la femme pétrit le pain et s'occupe de l'enfant. Le char « La vie sociale de Blumenau » montre diverses formes de sociabilités développées par les immigrants : le tir, le bolão et le Skat (jeu de cartes) pour les hommes et le Krächen (travaux d'aiguille) pour les femmes dont le rôle se cantonne à la sphère privée.

$\mathrm{Au}$ travers de leur engagement dans la représentation, les participants sont conviés chaque année à une réactivation de leur identité. Or ils tirent cette identité d'une mémoire historique sectaire et imprégnée de moralisme, construite sur des évidences partagées. Avec une historiographie sélective et réconfortante, une " Seconde histoire ", les fêtes reconstruisent le passé sur le mode de l'héroïsme. Elles réactivent des mythes germaniques et font revivre des actes fondateurs de la colonie. Des danses traditionnelles aux symboles culinaires, elles exhibent des différences, réélaborant la culture allemande et maintenant artificiellement un sentiment d'identité. Elles reconstituent ainsi des frontières que la vie quotidienne tend à abattre. Or il arrive aussi qu'elles s'intègrent dans un système 
de valeurs construit en continuité avec le quotidien. À Pomerode notamment, la culture allemande n'est pas seulement réélaborée lors des fêtes mais aussi quotidiennement avec l'usage de la langue ancestrale, le maintien de la pratique religieuse, un investissement maximal sur l'éducation et une vie associative efflorescente. Plus sobre et plus intime que l'Oktoberfest, la Festa Pomerana relève d'un isolement culturel plus fort. Les éléments carnavalesques y sont inexistants, ce qui témoigne de l'influence durable de la religion protestante dans cette communauté.

Les fêtes germano-brésiliennes peuvent donc être perçues comme des fêtes-célébrations. Les cortèges n'échappent pas aux normes et présentent des groupes sociaux hiérarchisés : la fanfare municipal, la Commission (CCO), le maire, les autorités municipales et régionales, la reine et les princesses, les mascottes (Fritz et Frida à Blumenau, Wilfried à Jaraguá), les groupes folkloriques avec les fameuses culottes de cuir, les Sociétés de chasse et de tir, les associations sportives, les pompiers, la police militaire, etc. Si elles relèvent du spectacle, elles présentent néanmoins une part de transgressif et peuvent être très excessives, dionysiaques, voire parfois orgiaques. Elles rompent temporairement et spatialement avec la réalité familière. A Blumenau, la ville est métamorphosée, décorée de banderoles noir-rouge-jaune et de guirlandes de fleurs, transformée en une immense scène festive. Des haut-parleurs invitent à danser la valse sur des refrains de chansons bavaroises, parfois chantés en portugais. La fête occasionne des dépenses inconsidérées et une grande consommation de bière, ce qui suscite chaque année de nombreux cas de violences. Un article intitulé «La violence a diminué de moitié lors des fêtes d'octobre » relève pour la période du 5 au 22 octobre 1995 les chiffres suivants : 263 vols de portefeuille, 34 vols de voiture, 76 accidents, 153 bagarres et 88 prises de stupéfiant (Jornal de Santa Catarina, 25 octobre 1995). Lors de l'observation, le chercheur est vite surpris par la « carnavalisation » d'une fête qui se veut traditionnelle. L'ambiance y est encore plus débridée qu'à Munich. Elle est une véritable explosion d'euphorie et de spontanéité, un monde à l'envers entretenu par les clowns, l'extravagance des costumes soi-disant traditionnels, les trachts à jupe courte donnant une touche érotique à la fête et la distribution gratuite de bière dans la rue par les chars «Wurstwagen », «Bierwagen » et «Shoppmotorad » suivis de la «Pisswagen », la voiture pour faire pipi. Cultivant l'autodérision et donnant libre cours au rire, à l'humour et à l'ironie, l'Oktoberfest peut apparaître comme une farce théâtrale montée pour les touristes, un carnaval stéréotypant des débris de culture allemande.

En outre, on peut la qualifier de fête de participation car elle resserre les liens sociaux et permet le rapprochement licite des sexes. À première vue, les distances hiérarchiques et sociales sont abolies. Loin de séparer et d'enfermer, elle offre la possibilité de construire des relations bien au-delà de la sphère associative. Lors du défilé, la frontière entre acteurs et spectateurs tend à disparaître. La population partage ses traditions avec des visiteurs d'origines diverses dont un grand nombre de jeunes en provenance de Florianópolis ou de l'intérieur de l'État, venus pour « faire la fête ». Ils sont également conviés à porter le costume traditionnel, ce qui leur permet d'entrer gratuitement dans les pavillons pour boire des chopes et danser sur les cuivres des orchestres qui mêlent parfois la samba au flonflon bavarois. L'ouverture est marquée par l'hymne national brésilien, chanté en chœur par la foule. En rassemblant des éléments de deux sociétés en contact, l'Oktoberfest masque les divisions ethniques. Si elle exhibe des différences, elle tend aussi à les dépasser en unifiant les contenus de consciences longtemps conflictuelles. Elle peut 
donc apparaître comme un processus de régulation des tensions, oscillant entre création et protection des valeurs, entre une créativité jaillissante et une construction institutionnelle inhérente à la culture germano-brésilienne.

\section{CONCLUSION}

La constitution d'une culture allemande au contact du Brésil révèle donc d'intéressantes procédures de réappropriation, de déconstruction et de reconstruction. Nous avons montré comment des biens culturels et politiques ont subi, suite à leur migration, des réaménagements et recompositions, lesquels ont donné lieu à de nouveaux modèles. On assiste à une acculturation du folklore germanique, un folklore mobile et reformulé, résultant du contact des générations et des groupes ethniques. Résistant à sa transplantation d'un continent à l'autre, il s'est décomposé puis s'est recréé à partir de résidus culturels réinterprétés par la sensibilité brésilienne.

Les fêtes germano-brésiliennes de l'État de Santa Catarina renvoient à l'histoire des colonies qui pendant longtemps formèrent des noyaux isolés, utilisant quotidiennement la langue allemande. Elles construisirent une forme de sociabilité existante dans leur pays d'origine, fondant des écoles, des églises et des institutions récréatives. Certains traits furent transférés et réélaborés, transmis de génération en génération avec plus ou moins d'intensité : la langue allemande, le comportement religieux, les habitudes alimentaires, l'organisation de l'espace domestique, la conception du travail et des loisirs, le rôle de la femme et l'intensité de la vie associative. Or, pendant les années trente, ces valeurs de la germanité furent réprimées par la campagne de nationalisation brésilienne. Une mémoire souterraine confinée au silence se constitua et elle trouva un moment propice à sa résurrection dans les années quatre-vingt. Situées à mi-chemin entre le souci d'une promotion touristique et la restauration d'un sentiment identitaire, les fêtes germano-brésiliennes sont avant tout des fêtes-célébrations. Si elles furent créées dans un objectif économique, elles ont aussi en commun la revalorisation d'une mémoire périodiquement refoulée et silencieuse. Elles célèbrent la population locale, associant la culture allemande au mythe du travail. Traduisant en brésilien l'orgueil des descendants allemands, elles apparaissent comme des expressions nouvelles et stéréotypées du Deutschtum, comme les formes d'actualisation les plus récentes de la culture germano-brésilienne.

\section{Références bibliographiques}

BASTIDE Roger (1957) Brésil, terre des contrastes, Paris, Hachette, pp. 228-259.

BASTIDE Roger (1970) Le prochain et le lointain, Paris, Cujas, pp. 157-189.

BLANCPAIN Jean-Pierre (1994) Migrations et mémoire germaniques en Amérique Latine, Strasbourg, Presses Universitaires de Strasbourg, pp. 48-49, 294.

CUCHE Denys (2008) Roger Bastide, le « fait individuel » et l'École de Chicago, Cahiers Internationaux de Sociologie, 2008/1, $\mathrm{n}^{\circ}$ 124, pp. 41-59.

DIETRICH Ana Maria (2007) Nazismo tropical? O Partido Nazista no Brasil, Núcleo de Estudos em História Oral da USP, Doutorado em História Social, Universidade de São Paulo. 
DOS REIS Dalton (1985) Diário da Tarde, 22 août 1985.

DREWS FILHO Henrique (2007) Abertura da 6e Festa Pomerana, Jornal do Médio Vale, 12 octobre 2007. DREWS FILHO Henrique (1989) Discurso proferido na abertura da 6e Festa Pomerana, Pomerode, 9 janvier 1989. ENTRES Gottfried (1929) Gedenkbuch zur Jahrhundertfeier deutscher Einwanderung im Staate Santa Catarina, Florianópolis, Livraria Central, Alberto Entres \& Irmão, p. 76.

FERREIRADA SILVA José (1988) Historia de Blumenau, Fundação “Casa Dr. Blumenau”, Blumenau. FERREIRA DA SILVA José (2000) Blumenau em Cadernos, Fundação Cultural de Blumenau, Blumenau, t. XLI, n 9-10, pp. 39-40, 85, 112.

FROTSCHER Méri (2007) Identidades Móveis, práticas e discursos das elites de Blumenau (19291950), Blumenau, Edifurb, Universidade Regional de Blumenau, p. 56.

RODRIGUES Genielli (2007) Começa hoje a 19e Schützenfest, Schützenfestzeitung, 4 octobre 2007. KLUG João (1991) Consciência Germânica e Luterismo na Comunidade Alemã de Florianópolis (1868-1938), Florianópolis, Dissertação em Historia da UFSC, p. 18.

KLUG João (1994) Imigração e Luteranismo em Santa Catarina. A comunidade alemã de Desterro, Florianópolis, Papa Livro.

MALENFANT Séverine (2006) La fête, mémoire collective et affirmation identitaire. Les fêtes historiques du Sud de l'Allemagne et leurs " textualités », thèse de Doctorat, soutenue le 9 novembre 2006, Université de Nantes.

MILANI Tatiana (2007) Fundação preserva os aspectos culturais da cidade, Jornal do Médio Vale, 12 octobre 2007, p. 5.

PFAU José Geraldo (1993) entretien réalisé le 24 juin 1993 à Blumenau par Maria Bernadete RAMOS FLORES (1997), Oktoberfest: Festa, Cultura e turismo na estação do chopp, Florianópolis, Editora Obra Jurídica Ltda., p. 50.

PILON TORRES Ivan (2007) Schützenfestzeitung, 4 octobre 2007, p. 3.

PROCHNOW Marcelo Heins (2007) Schützenfestzeitung, 4 octobre 2007, p. 8.

RAMOS FLORES Maria Bernadete (1997) Oktoberfest: Festa, Cultura e turismo na estação do chopp, Florianópolis, Editora Obra Jurídica Ltda., pp. 70-72.

RICHTER Klaus (1992) A sociedade colonizadora Hanseática de 1897 e a colonização do interior de Joinville e Blumenau, Florianópolis, UFSC, pp. 15-17, 47.

ROCHE Jean (1959) La colonisation allemande et le Rio Grande do Sul, thèse de Doctorat, Institut des Hautes Études de l'Amérique Latine, Université de Paris.

ROSENBROCK José Reinoldo (2007), Trentinos italianos começaram por aqui..., Jornal do Médio Vale, 12 octobre 2007, p. 29.

SCHNEIDER Oscar (2007) Jornal do Médio Vale, 12 octobre 2007, p. 4.

SCHRAMM Emilio (1993) entretien du 28 décembre 1993 réalisé par Maria Bernadete RAMOS FLORES (1997), p. 50.

SEYFERTH Giralda (1982) Nacionalismo e identidade étnica. A ideologia germanista e o grupo étnico teuto-brasileiro numa comunidade do Vale do Itajaí, Florianópolis, Fundação Catarinense de Cultura.

VARGAS Getulio (1935) A Nova Política do Brasil, vol. V, Rio de Janeiro, p. 116.

VARGAS Getulio (1940) A Palavra do Presidente Getulio Vargas em Blumenau, 10 de março de 1940, in Blumenau em Cadernos, t. XXXVIII, Julho de 1997, n 7, p. 31.

VOIGT André Fabiano (1997) A Imigração de Alemães para o Vale do Itajaí (1838-1850): Processo Informal de Ocupação de Terras, Blumenau em Cadernos, t. XXXVIII, nº 4, abril 1997.

WILLEMS Emilio (1946) A aculturação dos alemães no Brasil: estudo antropológico dos imigrantes alemães e seus descendentes no Brasi,. 2e ed. 1980, São Paulo, Nacional.

ZIMMER Rosely (1997) Pomerode a Cidade Mais Alemã do Brasil. As Manifestações de Germanidade de uma Festa Teuto-Brasileira, tese de doutorado, Departamento de Historia, UFSC, Florianópolis. 


\title{
La migration du folklore et des fêtes germaniques au Sud du Brésil
}

\author{
Séverine MALENFANT
}

Les fêtes germano-brésiliennes de l'État de Santa Catarina renvoient à l'histoire des colonies allemandes qui pendant longtemps formèrent des noyaux isolés, entretenant des liens avec la patrie-mère. Elles fondèrent des écoles, des églises et des institutions récréatives réélaborant la culture allemande. Or pendant les années trente, les valeurs du «Deutschtum » furent réprimées par le gouvernement brésilien et une mémoire clandestine se constitua, confinée au silence. Cette mémoire "souterraine " trouva toutefois un moment propice à sa résurrection dans les années quatre-vingt, grâce au plan de développement touristique. Si les fêtes furent fondées dans un objectif économique, elles ont aussi en commun la revalorisation d'une mémoire refoulée et silencieuse et la célébration d'une partie de la population locale. Elles apparaissent comme les formes d'actualisation les plus récentes de la culture germano-brésilienne, traduisant en brésilien l'orgueil des descendants d'Allemands.

\section{Germanic Folklore and Feasts in Southern Brazil}

\section{Séverine MALENFANT}

The German festivals of the State of Santa Catarina in Brazil return us in the story o the German colonies which formed for a long time insulated cores, maintaining links with the fatherland. They founded schools, churches and institutions re-working the German culture. During the thirties, the values of "Deutschtum" were repressed by the Brazilian government and an underground/secret memory was formed, confined in silence. However this "subterranean" memory found a moment convenient to its resurrection in the eighties, thanks to the plan of tourist development. If these festivals were founded in an economic objective, they have so in common the revaluation of a repressed and silent memory and the celebration of a part of the local population. They appear as the most recent forms of actualization of the German-Brazilian culture, translating into Brazilian the pride of the German descendants.

\section{La migración del folklore y de las fiestas germano-brasileñas en el Sur del Brasil}

\section{Séverine MALENFANT}

Las fiestas germano-brasileñas del Estado de Santa Catarina reenvían a la historia de las colonias alemanas que durante mucho tiempo formaron núcleos aislados, manteniendo lazos con la madre-patria. Fundaron escuelas, iglesias y instituciones recreativas que reelaboraban la cultura alemana. Durante los años treinta, los valores de «Deutschtum» fueron reprimidos por el gobierno brasileño y una memoria clandestina se constituyó, confinada al silencio. Esta memoria «subterránea» encontró no obstante un momento propicio a su resurrección en los años ochenta, gracias al plano de desarrollo turístico. Si las fiestas fueron fundadas con un objetivo económico, tienen también en común la revalorización de una memoria rechazada y silenciosa y la celebración de una parte de la población local. Aparecen como las formas más recientes de actualización de la cultura germano-brasileña, traduciendo en brasileño el orgullo de los descendientes de alemanes. 